\title{
THERMAL SIMULATION OF CNC MILLING MACHINE DRIVES
}

\author{
Branislav FECKO, Tibor VINCE \\ Department of Theoretical and Industrial Electrical Engineering, Faculty of Electrical Engineering and Informatics, \\ Technical University of Košice, Letná 9, 04200 Košice, Slovak Republic, tel. +421 55602 2706, \\ E-mails: branislav.fecko@tuke.sk, tibor.vince@tuke.sk
}

\begin{abstract}
The publication deals with the design of thermal simulation of CNC milling machine drives. The first part of the publication defines the individual parts of the thermal model concept and their mutual influence. Subsequently, simulations of drives were created. The first thermal model is defined for a stepper motor which is a drive for the linear axes of a CNC milling machine. Subsequently, the design of the thermal drive of the spindle is analysed, which uses a DC motor with permanent magnets. Using previous models of the drive, a model of the entire CNC milling machine was designed. In the last part, the model was compared with real measurements, which evaluated the tolerances of the system.
\end{abstract}

Keywords: CNC milling machine, stepper motor, DC motor, thermal model, simulation

\section{INTRODUCTION}

The main reason why we focus on modelling the $\mathrm{CNC}$ system is its complexity and combination of electrical and mechanical engineering. Each CNC device has its specific task for which it is designed. It is necessary for the $\mathrm{CNC}$ machine to process with a certain accuracy and reliability. That is why one of the most common problems related to CNC machines is their accuracy, service life and cooling, which are investigated and treated in various ways. We can partially connect all the mentioned problems with the heat generated in the $\mathrm{CNC}$ machine during its operation. The accuracy of the device is affected by the thermal expansion of the construction materials of the machine and its other parts. The service life of a CNC milling machine is directly related to the service life of its drives; in the case of electric drives, it is known that increasing the temperature of the motors above the operating value reduces the service life of the motor. The cooling itself in CNC milling machines is directly related to the heat, which includes the cooling of the machining tool or the cooling of the machine drives, which generate heat during their operation. In the case of appropriate use of the possibility of prediction of the generated heat of the $\mathrm{CNC}$ milling machine, it is possible to minimize the influence of temperature on the mentioned problems or to predict their occurrence. For these reasons, this work deals with the investigation of the thermal model of a CNC milling machine. The thermal model will be created in Matlab Simulink software.

\section{I.THE SYSTEM CONCEPT}

During the design of the thermal model, it was necessary to consider all ongoing processes during the milling process. Fig. 1 shows a block diagram of a thermal model of a CNC milling machine [1]. The block diagram presents the main parts of the system and their interaction. The blue and black lines represent the heat transfer between the connected blocks. Heat transfer is formed by energy transfer by conduction, convection and radiation [2]. In most cases, one type of transmission predominates over the others to such an extent that the remaining types of transmission can be neglected due to the simplification of the model. The determination of specific methods of heat transfer between parts of a CNC milling machine can be found in the description of the created thermal model.

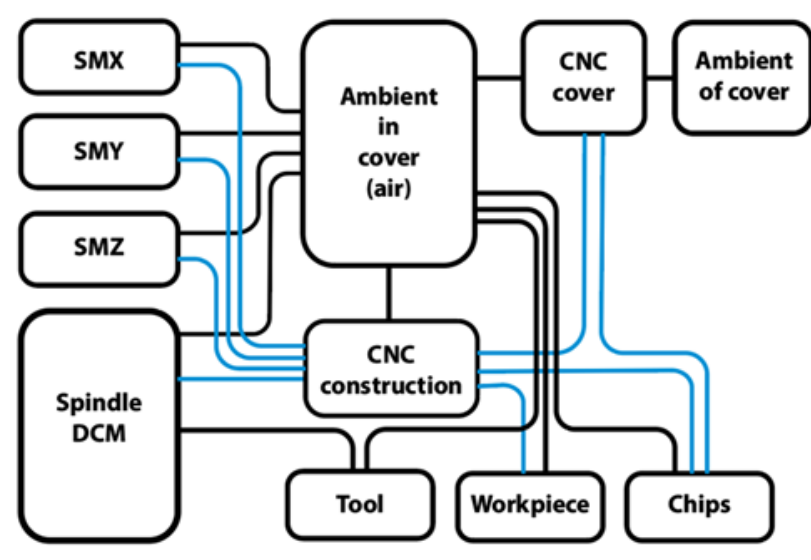

Fig. 1 The concept of thermal model

We used the block diagram shown in Fig. 1 to create a thermal model. The given block diagram describes the following interaction of the system. During milling, heat is exchanged from the stepper motors into the environment in the cover and construction of the $\mathrm{CNC}$ machine. The heat generated by the spindle is transferred to the CNC structure and the environment. During milling, $95 \%$ of the consumed power is converted into heat [3]. The heat generated during material cutting is distributed between the tool, the workpiece and the chip. Part of the heat generated in the tool is transferred to the spindle and the environment. The largest part of the heat generated during milling is absorbed by the chip, the smallest part is absorbed by the workpiece. The heat from the workpiece and chips spreads into the environment, the construction of the CNC milling machine and the machine cover. The $\mathrm{CNC}$ machine is located in the cover, so the environment in the cover interacts with each part of the CNC machine. The influence of the surrounding environment on parts of the CNC machine is weakened by the cover of the $\mathrm{CNC}$ device [4].

\section{THERMAL MODEL OF STEPPER MOTOR}

The first part describes the simulation of a stepper motor. Fig. 2 shows thermal model of stepper motor. The model consists of the control input $m \_s p e e d \_x$, the stepper motor controller and the stepper motor module. The Stepper Motor module is the main part of the described 
simulation. It is possible to select the heat loss simulation in the module settings. These settings will allow you to simulate the losses divided between iron losses and Joule losses. The thermal model of the stepper motor is supplemented by a block of thermal mass, which represents the material formed by the stator. The winding of the stepper motor is located in the stator. Therefore, a conduction heat transfer block is inserted between the stator and the winding. The motor rotor is a source of heat loss in the iron. The heat transfer between the stator and the rotor is simulated by conduction and convection. The heat transfer by the flow is introduced due to the air gap between the rotor and the stator. The heat transfer through the line takes into account the contact of the bearings on which the rotor is located. The output from the stepper motor subsystem is the stator temperature and the rotor temperature due to contact with other parts of the $\mathrm{CNC}$ system and subsequent heat transfer [5].

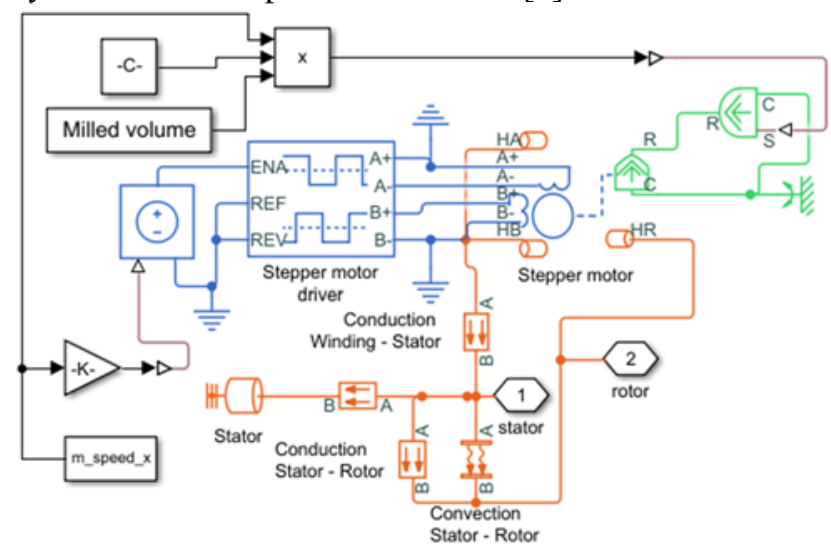

Fig. 2 Thermal model of stepper motor

The controller and engine block are in Averaged mode. This mode allows the motor to be controlled by defining the rotational speed. The $m \_s p e e d \_x$ block reads data from a Matlab file that defines the motion of the stepper motor based on the G-code analysis. Another data read is the Milled volume signal, which defines the current drive load. The milled volume affects the force that the stepper motor must exert when moving during the milling process. The load of the stepper motor is simulated by a source of ideal torque, which creates a force acting against the torque of the stepper motor. The magnitude of the generated torque depends on the speed of movement, the load of the stepper motor and the machinability constants of the material.

\section{THERMAL MODEL OF DC MOTOR WITH PERMANENT MAGNETS}

The simulation of a DC motor with permanent magnets is showed in Fig. 3, includes a PWM modulation block, an h-bridge, a DC motor, a load and blocks representing the thermal conditions of the drive. The model simulates Joule losses created in the winding, hysteresis losses and losses created by eddy currents, which are sources of heat in the rotor. The winding and the rotor are presented as separate thermal masses, between which there is heat transfer by conduction. The stator part of the motor is divided into two parts. The distribution was defined due to the effect of the fan on the engine cooling. A conduction heat transfer is defined between the inner part of the stator and the outer part of the stator. As with a stepper motor, the stator is housed in bearings which ensures heat transfer between the stator and rotor by convection [6].

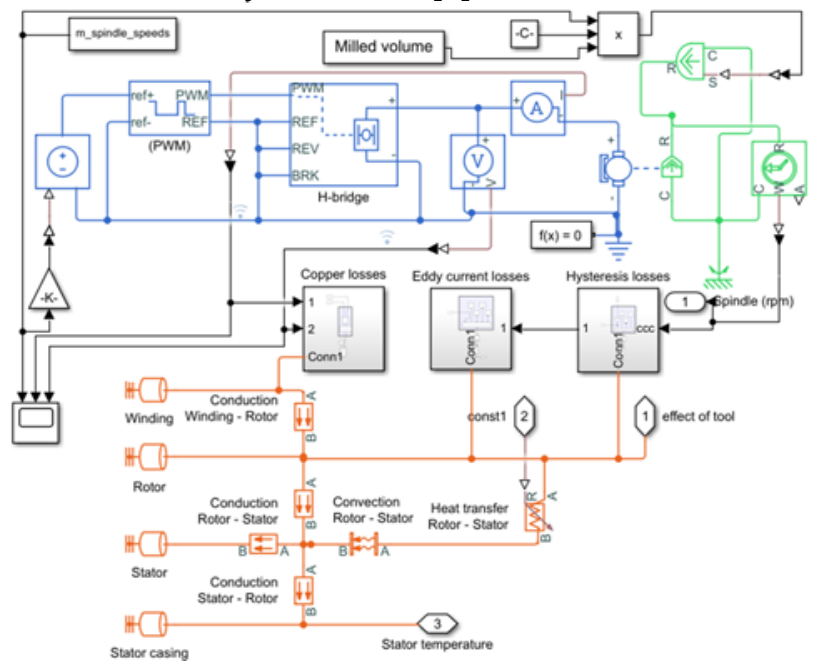

Fig. 3 Thermal model of DC motor (spindle)

As the spindle speed increases, the resistance value decreases, ensuring greater heat transfer. Heat transfer through a variable resistor replaces heat transfer by convection, conduction and radiation [7]. The $m \_s p i n d l e \_s p e e d$ block imports the spindle control signal. Another imported control signal is the Milled volume, which affects the current milling power.

\section{COMPLETE THERMAL MODEL OF CNC MILLING MACHINE}

Fig. 4 shows a thermal model of the operation of a CNC milling machine. The SMX, SMY and SMY subsystems are blocks of stepper motors of individual axes. The DCM subsystem includes a spindle simulation. Other additional subsystems in the simulation include the influence of the fan and the calculation of coefficients for controlling the variable thermal resistance. Heat transfer between parts of the system is defined in the way that is most involved in a given transfer. The remaining transfer methods are either included in the primary heat transfer method or are replaced by a block of variable thermal resistance. In the simulation, blocks of variable thermal resistance were used to simulate the effect of the spindle fan. The coefficients were obtained by estimating the parameters. Each heat transfer simulated by the thermal resistance required its own coefficient, because the influence of the fan on the individual components was different. In the used method of simulation, it is assumed that the individual parts of the CNC milling machine are formed by homogeneous bodies with the same thermal properties in the whole body. When creating a model, it is necessary to take into account the given simplification and adapt the model so that it best describes the simulated system with respect to the requirements. The description of the use of specific blocks of the model is as follows. Part of the interaction of drives is simulated by blocks located in area 1. The blocks simulate the transfer of heat by radiation and swirling of air, which does not fall into the assumption of a homogeneous environment in the housing of the CNC milling machine. Variable thermal resistors mediate the heat exchange 
between the stepper motors and the environment. The conduction heat transfer blocks in Part 3 simulate the heat transfer between stepper motors and the construction of a CNC milling machine. The environment in the cover (air) interacts with the $\mathrm{CNC}$ structure, the cover and the environment outside the cover by the heat transfer blocks shown in section 4 . The interaction of the environment in the cover and outside the cover occurs when the cover is opened when changing the workpiece, tool or imperfect seal. Parts of model 5,6,7 are associated with heat generation in the milling process. The blocks in section 7 define the heat generated during the machining process, which is then distributed between the tool, the workpiece and the chip. The distribution ratio of the heat generated during milling is determined by the blocks in area 6 . Part of the heat generated in the tool is transferred by the conduction of the spindle. The rest of the heat generated during milling is released into the environment through the tool, workpiece and chip. The simplification did not have a negative effect on the simulation results.

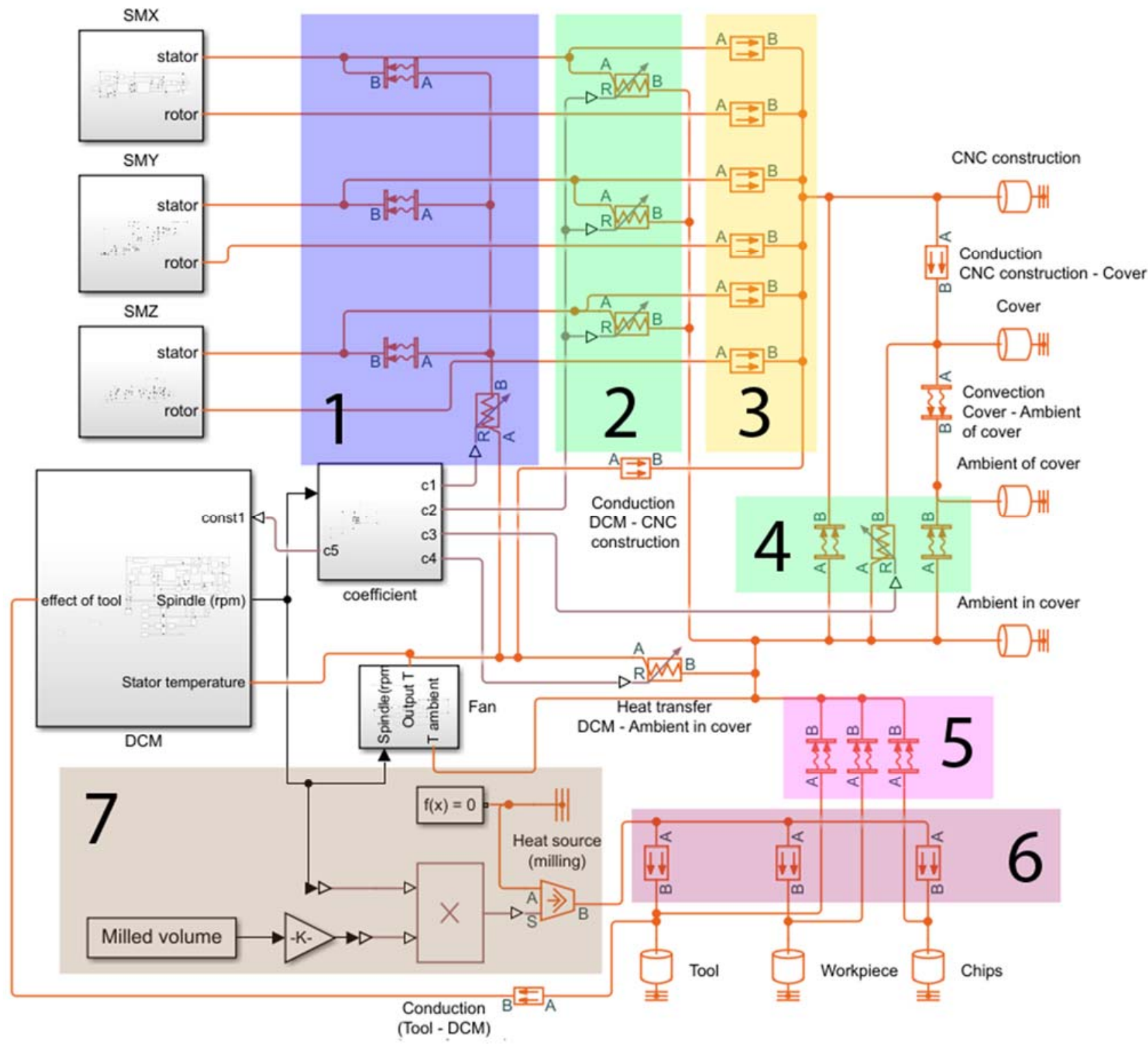

Fig. 4 Thermal model of CNC milling machine

\section{RESULTS}

Table 1 shows the values of the drive tolerances in comparison with the real system. By considering the resulting parameters of the model, we can state that the model meets the assumptions of a functional thermal model of a CNC milling machine. In the next chapter we will focus on the use of the model in a practical solution of temperature prediction in a monitoring system.

Table 1 Drives model tolerance

\begin{tabular}{|c|c|c|}
\hline Actuator & $\begin{array}{c}\text { Absolute } \\
\text { tolerance }\left[{ }^{\circ} \mathbf{C} \text { ] }\right.\end{array}$ & $\begin{array}{c}\text { Relative } \\
\text { tolerance [\%] }\end{array}$ \\
\hline Spindle & 1,3 & 2,7 \\
\hline SMX & 0,5 & 1,2 \\
\hline SMY & 0,7 & 1,8 \\
\hline SMZ & 0,6 & 1,5 \\
\hline
\end{tabular}


A general comparison of the temperature curves of the thermal model and the real CNC device is shown from Fig. 5 to Fig. 8.

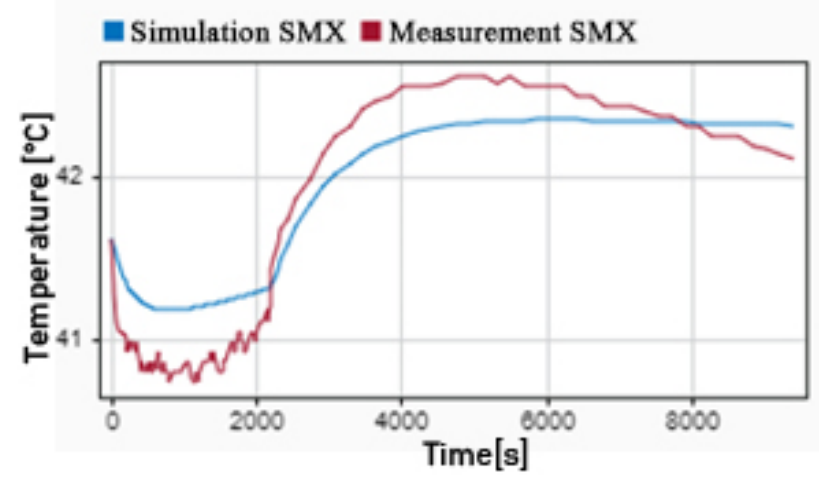

Fig. 5 Temperature of stepper motor axis-X

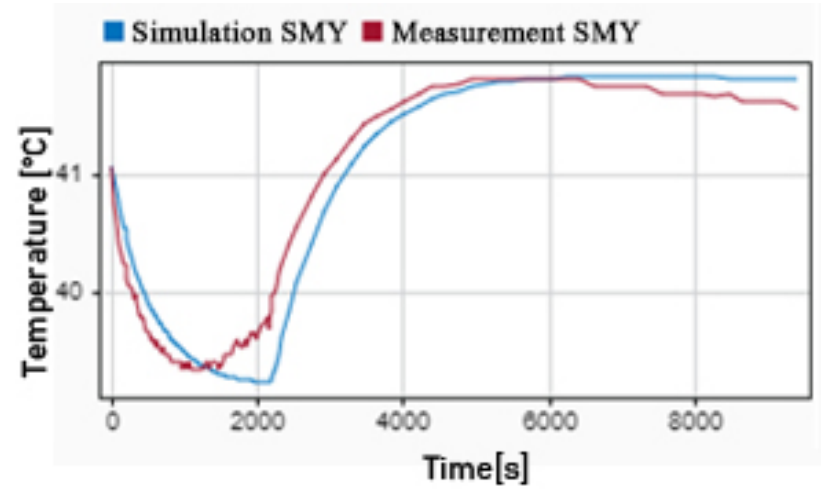

Fig. 6 Temperature of stepper motor axis-Y

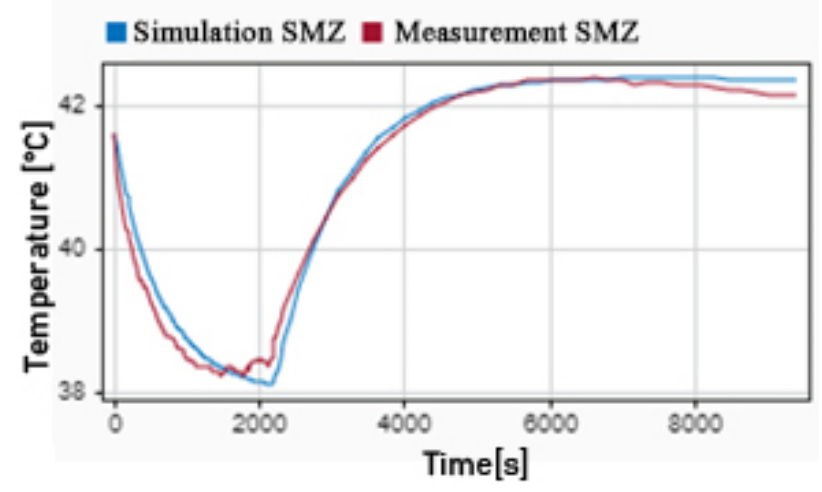

Fig. 7 Temperature of stepper motor axis-Z

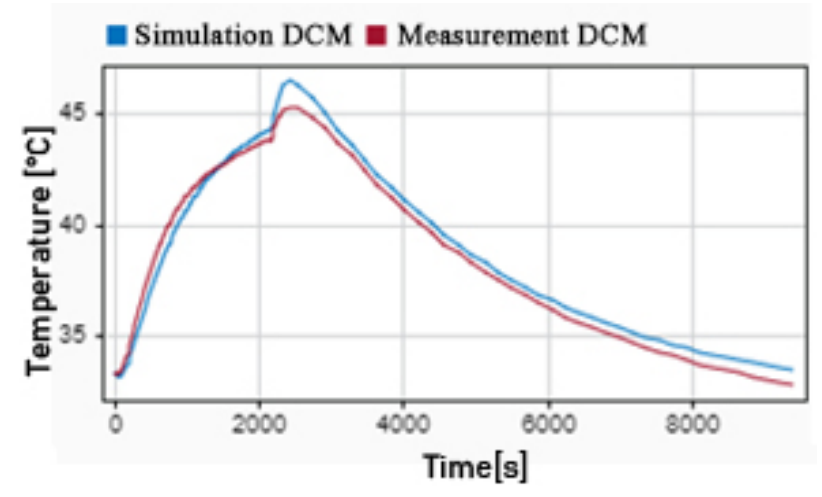

Fig. 8 Temperature of DC motor (spindle)

\section{CONCLUSIONS}

The thermal model of the device was created in the Matlab Simulink environment. To create the correct simulation, it was necessary to obtain all available and measurable parameters of drives and other parts of the machine. The Parameter Estimator tool was used to obtain unknown constants. Simulations include calculations of drive parameters, partial simulations of individual parts and a complete thermal model of a CNC milling machine.

In the last part, a verification and assessment of the use of the entire system was performed. In case of correct operation of the model and the CNC machine, the model does not exceed the maximum relative tolerance of $3 \%$ and the absolute tolerance of $1,5^{\circ} \mathrm{C}$. The model works with sufficient accuracy to use the model to control the operation of the CNC equipment and allows you to correctly detect possible failures of the monitored system.

In the future, the model will be used in practice, it will be implemented in the monitoring system [8]. By its implementation we obtain predictive data which will be compared with the current value. From the difference between prediction and current measurement, it is possible to determine conclusions about the state of the $\mathrm{CNC}$ equipment.

\section{REFERENCES}

[1] FECKO, B.: NÁVRH A RELIZÁCIA 3 - OSOVEJ CNC FRÉZKY. Technická univerzita $\mathrm{v}$ Košiciach, 2016.

[2] NOVÁK, P.: Elektrické teplo: Základy teórie elektrických ohrevov a aplikácie. Košice: Equilibria, s.r.o, 2010. 514 s. ISBN 978-80-89284-48-1

[3] VASILKO, K.: Analytická teória trieskového obrábania. Fakulta výrobných technológií TU v Košiciach, 2007, ISBN 978-80-8073-759-7

[4] ZHU, J.: Robust thermal error modeling and compensation for CNC machine tools. University of Michigan, 2008.

[5] TOMY, N. M. - FRANCIS, J.: Field oriented sensorless position control of a hybrid stepper motor with extended Kalman filter. In: 2016 10th International Conference on Intelligent Systems and Control (ISCO). IEEE, 2016. p. 1-5.

[6] WAHAB, A. A. - ABDULLAH, N. F. - RASID, M. A. H.: Commutator fault detection of brushed DC motor using thermal assessment. In: IOP Conference Series: Materials Science and Engineering. IOP Publishing, 2019. p. 012057.

[7] MATHWORKS: Simulink Documentation [online]. Dostupné na internete : < https://www.mathworks.com/help/simulink/index.html $>$.

[8] FECKO, B. - VINCE, T.: Design of temperature measurement system and data visualization. In: Journal of Industrial Electrical Engineering, vol: 4, issue: 3, Košice: TU, 2020 S. 1-3. - ISBN 2454-0900 
Received August 6, 2021, accepted October 8, 2021

\section{BIOGRAPHIES}

Branislav Fecko was born in 1994. He received his engineering degree in 2018 at the Technical University of Košice, in Industrial Electrical Engineering. He is currently a $\mathrm{PhD}$ student at the Department of Theoretical and Industrial Electrical Engineering. His area of research is focused on measurement, data analysis and the creation of simulation models.
Tibor Vince was born in 1979. He finished his engineering study in 2003 at the Technical University of Košice, Department of Industrial Engineering. In 2011 he finished his PhD study at the Technical university of Košice, in field of study Theoretical electrical engineering. From 2008 he has been working at the Technical University in Košice first as an assistant professor at the Department of Theoretical and Industrial Electrical Engineering and from 2017 he is in the position of associated professor at the same department. He is an author of several patents, scientific board member and reviewer of several international journals. 